\title{
Leprosy neuropathy: clinical presentations
}

\author{
Neuropatia da lepra: apresentações clínicas \\ Osvaldo J M Nascimento
}

\begin{abstract}
Leprosy is a chronic infectious peripheral neuropathy caused by Mycobacterium leprae. The different clinical presentations of the disease are determined by the quality of the host immune response. Early detection of leprosy and treatment by multidrug therapy are the most important steps in preventing deformity and disability. Thus the early recognition of the clinical leprosy presentation is essential. Mononeuritis, mononeuritis multiplex (MM), polyneuritis (MM summation) are the most frequent. The frequent anesthetic skin lesions are absent in the pure neuritic leprosy presentation form. Isolated peripheral nerve involvement is common, including the cranial ones. Arthritic presentation is occasionally seen, usually misdiagnosed as rheumatoid arthritis. Attention should be given to autonomic dysfunctions in leprosy. There are clinical presentations with severe neuropathic pain - painful small-fiber neuropathy. Leprous late-onset neuropathy (LLON) clinical presentation should be considered facing a patient who develop an inflammatory neuropathy many years after a previous skin leprosy treatment.
\end{abstract}

Keywords: leprosy neuropathy, clinical presentations, pure neuritic form, neuropathic pain, leprosy late-onset neuropathy, arthritic leprosy, autonomic leprosy, review.

\section{RESUMO}

A hanseníase é uma neuropatia periférica infecciosa, crônica, causada pelo Mycobacterium leprae. As diferentes apresentações clínicas são determinadas pela qualidade da resposta imune do hospedeiro. 0 diagnóstico precoce e a multi-droga terapia são os passos mais importantes na prevenção de deformidades e incapacidades. Dessa forma, o reconhecimento precoce da apresentação clínica da hanseníase é essencial. Mononeurites, mononeurites múltipla (MM), polineurite (superposição de MM) são as mais frequentes. As frequentes lesões anestésicas de pele estão ausentes na forma neurítica pura. Comprometimento de nervo isolado é comum, inclusive os cranianos. Apresentação com artrite é ocasionalmente vista, erroneamente diagnosticada como artrite reumatóide. Atenção deve ser dada às disfunções autonômicas na hanseníase. Há apresentações clínicas com dor neuropática grave - neuropatia dolorosa de pequenas fibras. Neuropatia de início tardio (LLON) é apresentação clínica que deve ser considerada frente a paciente que desenvolve neuropatia inflamatória muitos anos depois de tratamento prévio da lepra cutânea.

Palavras-Chave: neuropatia da lepra, apresentações clínicas, forma neural pura, dor neuropática, neuropatia de início tardio, lepra artrítica, neuropatia autonômica, revisão.

Leprosy, a chronic infectious disease caused by $M y$ cobacterium leprae, identified by G. H. A. Hansen in 1873, is one of the most common treatable peripheral neuropathy in the world. Leprosy causes a 'mononeuritis multiplex' of immunological origin that results in autonomic, sensory and motor neuropathy'. The skin, the peripheral nerves, the nasal mucosa, eyes, and the reticulum-endothelial system are the preferred target sites for this infection. The clinical and pathological manifestations are determined by the natural resistance of the host to invasion of M. Leprae. It still remains a stigmatizing disease. Leprosy can be effectively treated with multidrug therapy (MDT) before disability appears. The early diagnosis of leprosy often leads to a less amount of disabilities. This review has the objective to call attention for the clinical presentations of leprosy neuropathy in clinical practice.

\section{EPIDEMIOLOGY}

The World Health Organization (WHO), in 2009, informed that 17 countries (including India, and Brazil) reported more than 1000 new cases, performing 94\% of the new globally detected. Some sporadic cases can be seen in countries receiving immigrants from underdeveloped countries. This is

From the Department of Neurology, Universidade Federal Fluminense, UFF, Rio de Janeiro RJ, Brazil.

Correspondence: Osvaldo J.M Nascimento, MD, PhD, FAAN; Rua Siqueira Campos 53/1204; 22031-071 Rio de Janeiro RJ - Brazil;

E-mail:osvaldo_nascimento@hotmail.com

Support: FINEP, MCTI-CNPq.

Conflict of interest: There is no conflict of interest to declare.

Support: MCTI-CNPq, FINEP. 
the USA case where leprosy incidence is increasing in some States. In a North and South America Peripheral Neuropathy Project we have observed a relative higher percentage of leprosy when comparing both USA and our patients in the group of infectious neuropathy, respectively 26/53 (49\%), and $39 / 141(28 \%)^{2}$. European countries also have sporadic cases. In Spain, for example, there are cases involving immigrants and also native Spaniards ${ }^{3}$.

\section{M. leprae infection}

M. leprae is morphologically indistinguishable from $M$. tuberculosis. It damages both myelinated and unmyelinated nerve fibers followed by replacement of functional tissue by conjunctive tissue - fibrosis ${ }^{4}$. The pathogenesis of nerve injury can be summarized with the localization of the M. leprae to nerve, Schwan cell infection and self responses, demyelination and axonal atrophy, accompanying with oedema and characteristic inflammation. The immune response to leprosy depends on the genetic susceptibility. HLA genes also may influence the type of leprosy that develops during infection (HLA class II) $)^{5}$. Immunogenicity is fundamental in the development of clinical presentations and also in the management of leprosy neuropathy.

\section{Leprosy classification}

The current accepted classification for leprosy was made by Ridley and Jopling in 1966. It was based on clinical, histological and immunological criteria. It subdivided leprosy in groups: tuberculoid ( $\mathrm{T}$ ), borderline tuberculoid (BT), borderline (BB), borderline lepromatous (BL) and lepromatous (L). A minor form was added later: indeterminate (I). As it is well known, leprosy forms does not depend of the bacilli itself but on the immune response of the host. In LL macrophages are unable to kill bacilli; on the other hand, in BL there is an intense cell-mediated immunity response able to destroy $b a$ cilli. There is also a clinical presentation of leprosy without any skin lesions known as pure neuritic form (PNL). There is also a condition known as "silent neuropathy" (SN). It is characterized by the impairment of sensory and motor functions without skin signs, nerve tenderness, pain, paraesthesia or numbness symptoms of neuritis. It is also called "quiet nerve paralysis" ${ }^{1}$.

\section{Clinical presentation of leprosy}

Leprosy is a neuropathy itself and it is perhaps the best model of inflammatory neuropathy. Neural involvement includes damage to the nerve trunks as well as to the cutaneous nerve endings. Sensory, autonomic and motor symptoms are seen due to the inflammation or as a consequence of reactive regenerative process. Sensory clinical presentations are the most common and usually open the clinical picture. Small-fibers neuropathies predominate, mainly in the early stages. Large fibers are involved later or, in specific cases, can predominate. Predominantly motor fiber compromise can also be seen but it is less common. Leprosy presentations include mononeuritis, mononeuritis multiplex and polyneuritis (moneuritis multiplex summation).

\section{Mononeuritis and mononeuritis multiplex}

Mononeuritis is the most common presentation of leprosy, and the nerves in the upper limbs are more often affected than those of the lower. The most commonly involved nerves are the ulnar, median, posterior auricular, superficial radial, common fibular, superficial fibular and posterior tibial ${ }^{4}$. Also in PNL form, mononeuritis is the most common presentation, comprising $79 \%$ of a 19 leprosy patient series ${ }^{7}$. In this series mononeuritis multiplex was seen in $10.5 \%$ of cases.

The inflammatory process causes an increase in nerve thickness size. They become usually enlarged and painful upon palpation. Sensory and motor signs and symptoms are then observed. Isolated ulnar nerve thickening represents $60 \%$ of those cases with just one nerve affected. Difficulties for the diagnosis can occur in some pure ulnar palsy cases. Only a dorsal ulnar nerve superficial branch biopsy confirms leprosy diagnosis ${ }^{4}$. Sonography and electrophysiology were complementary for identifying ulnar nerve neuropathy in 21 consecutive Brazilian patients with leprosy, with clinical symptoms as the reference standard ${ }^{8}$. This report reinforced the role of sonography in the investigation of leprosy ulnar neuropathy. Ultrasound performed at the elbow is able to differentiate ulnar palsy due to leprosy from entrapment at this site ${ }^{9}$.

Posterior tibial nerve involvement in leprosy causes anesthesia on foot sole that may be followed by ulcer, deformity, with severe foot bones compromise - neuropathic foot.

In many cases, where there is involvement of two nerves of the same limb, the association between ulnar and median nerves are mostly common. The ulnar nerve is usually involved bilaterally in different stages of the disease progression. Median nerve compromise is rarely seen. We have recently reported six cases of isolated median neuropathy as the first sign of leprosy, selected from patients with an exclusively sensory complaint as the initial symptom. Three of the patients had PNL, and 3 had skin lesions. Clinical median nerve function impairment was confirmed by neurophysiological testing and histopathology. Both mononeuritis and mononeuritis multiplex were observed. This case series demonstrates an additional form of presentation of leprosy, which, if not diagnosed and treated in time, may lead to permanent disability ${ }^{10}$.

Cranial nerve involvement in leprosy does not appear to be so rare. There is clinical evidence of cranial nerve involvement in $18 \%$ of patients with leprosy. The fifth and seventh cranial nerves are the most affected. Out of 100 leprosy patients in a consecutive series 22 had cranial nerve involvement. Facial nerve was the most commonly involved (10/22), 
followed by olfactory (9/22), trigeminal $(7 / 22)$ and auditory $(3 / 22)$ nerves $^{11}$. Isolated involvement of the sixth cranial nerve leading to lateral rectus muscle palsy during type 1 reaction in a BL male patient was recently reported ${ }^{12}$. An anedoctal case of leprosy with multiple cranial neuropathy mimicking Melkerson Rosenthal syndrome was decribed in India ${ }^{13}$.

Aside the cutaneous and neural involvement, rheumatological manifestations are frequent in leprosy, although often underrecognized. Forty-four cases were identified in a retrospective study (January 2001-September 2010) in northern India ${ }^{14}$. The authors concluded that leprosy may mimic rheumatoid arthritis (RA), spondyloarthropathy or vasculitis. Pure neuritic variety and spontaneous type 2 leprosy reaction pose unique diagnostic challenges. Studying 33 patients, Salvi and Chopra ${ }^{15}$ concluded that serological rheumatoid factor and antinuclear antibody were often false positive. Several patients of RA were on long-term supervised methotrexate. Rheumatologists should be aware of this clinical mimic to avoid errors in diagnosis and management.

Electrophysiological tests, including sensory and motor nerve condution studies, and electromyography are very useful for leprosy early diagnosis and follow-up.

\section{Polineuropathy}

In a few cases there is a distal neuropathy with temperature and pain anesthesia, without muscle weakness due to a mononeuritis multiplex summation. In these cases tendon reflex may be normal. Electrodiagnostic tests may be normal or show concomitant involvement of large myelinated fibers, although there is no proprioceptive loss. It seems that the small fibers are most involved. In some patients there is no skin lesions comprising the PNL form. In these cases only the nerve biopsy can establish the diagnosis of leprosy ${ }^{4,7}$.

Leprosy is known to preferentially involve only the exteroceptive sensations but proprioceptive sensory loss has been rarely described in subjects with leprosy. Van Barkel et al. ${ }^{1}$ found joint position sense abnormalities in only seven of 303 LL patients. Pandya et al. (1994) reported six patients who presented with progressive sensory ataxia and had pseudo-athetosis of fingers and generalized areflexia. Authors suggested that proprioceptive loss in those patients was a result of 'leprous ganglionitis'. Misra et al. ${ }^{16}$ have reported a single patient with type 1 reaction, who clinically had pseudo-athetosis. There is a report of a patient demonstrated to have not only ganglionitis, but also more proximal involvement in the form of a spinal cord granuloma on gadolinium-enhanced magnetic resonance imaging scan of the cervical spinal cord. Electrophysiological studies corroborated proximal involvement ${ }^{17}$. Symmetrical neuropathies outnumbered mononeuritis multiplex (12:7) in a series of 19 patients in Mumbai, India, presenting proprioceptive loss in leprous neuropathy ${ }^{18}$.

\section{Autonomic dysfunction in leprosy}

Regional autonomic signals and symptoms, most involving sweating process, are seen in leprosy. Vasomotor reflex was impaired in at least one finger in 33/76 (43\%) patients by means of laser Doppler velocimetry in 76 Brazilian patients ${ }^{19}$. Autonomic nerve lesion was more frequent than somatic lesions and was strongly related to the immune-inflammatory reaction against $M$. Leprae.

Compared with controls, in a series of 25 leprosy patients the R-R interval variations were found to be reduced during both resting and deep forced hyperventilation. The authors concluded that sensory nerve damage is accompanied by autonomic involvement ${ }^{20}$. Autonomic function and NCS were significantly more altered in $\mathrm{MB}$ than $\mathrm{PB}$ patients in a prospective clinical study we have recently reported including 10 $\mathrm{PB}$ and $12 \mathrm{MB}$ patients evaluated at diagnosis and one year after cessation of $\mathrm{MDT}^{21}$.

\section{Nerve enlargement}

Nerve thickening in neuritic leprosy ranges from 40 to $75 \%$. Nerve enlargements were found in almost half of a Brazilian case series presenting polyneuritic form (overlapping neuritis) we have studied ${ }^{4}$. In a multicenter study including $303 \mathrm{MB}$ patients in North India nerve enlargement was seen in $94 \%^{1}$. After leprosy treatment nerve may gradually shrink, but they remain abnormally firm.

\section{Leprosy reactions}

Leprous patients may develop hypersensibility host responses, thus interrupting the stable and chronic course of the disease. These are known as leprosy reactions. Type 1 reaction or reversal reaction (RR) is a late cellular hypersensibility reaction type IV. It occurs in B and BL. The reaction usually appears during the first months of treatment. Previous lesions become steadily more swelled up, reddened and even ulcerate resulting in pain upon minor trauma. Fever, malaise and anorexia may be present. Facial swelling as well as swelling of the legs and upper limbs is characteristic. Type 2 reaction or erithema nodosum leprosum (ENL) is an acute inflammatory condition involving a TNF-alfa and immune complex mediated immune response with infiltration of Th2-cells. It occurs most frequently in L patients, less frequently in BL patients and is more commonly seen in patients with high bacterial index. Nodules and painful, raised red papules are characteristic. These nodules may be accompanied by uveitis, iridocyclitis, episcleritis, neuritis, arthritis, dactilitis, lympohadenitis and orchitis. Fever, prostration, anorexia as well as other symptoms are frequent ${ }^{22}$.

\section{Leprosy late-onset neuropathy}

Relapse in leprosy is a reoccurrence of the disease at any time after the completion of MDT. There are different causes of relapses: an inadequate MDT due to misclassification of 
the disease, a premature stop of MDT or a poor compliance. Sometimes even with adequate MDT the relapse is due to multiplication of persistent bacilli, or drug resistance. The relapse may be in the form of late reversal reaction or due to reinfection.

Occasionally there are patients who developed delayed nerve impairment years after MDT, which could not be explained by relapses or reactions. They may have acute mononeuropathy or a chronic and slowly progressive form of multiple mononeuropathy or polyneuropathy. There was no activity of leprosy. We have considered this form as a leprosy late-onset neuropathy (LLON) ${ }^{23}$. New cases were included and recently reported by our group emphasizing LLON presentation form ${ }^{24}$. Probably it represents an immune reaction due to the persistence of the bacillus antigen ${ }^{25}$. Recently we also reported two LLON cases presenting as an ataxic polyneuropathy (LLON - ataxic presentation) (Peripheral Nerve Society Meeting, Saint Malo, Fr, June 2013). A better understanding of LLON clinical features and physiopathology is needed for a better management.

\section{Leprosy and neuropathic pain (NP)}

NP due to small-fiber damage is a well-recognized feature of leprosy neuropathy. Out of 275 interviewed Chinese patients with leprosy, 126 (45.8\%) reported having symptoms suggestive of neuropathic pain. The pain was severe in $70(55.5 \%)$ and moderate in $49(38.9 \%)$ patients. Neuropathic pain is not uncommon in both $\mathrm{MB}$ and $\mathrm{PB}$ patients who have completed effective antimicrobial treatment ${ }^{26}$. Painful symptoms were also referred by $42.1 \%$ of 19 PNL patients ${ }^{6}$. The presence of A-waves in conduction studies correlates well with pain complaints of neuropathic characteristics in leprosy patients, especially in those with type 2 reaction ${ }^{27}$. Probably, such response shares similar mechanisms with the small-fiber dysfunction seen in these patients with NP, such as demyelination, intraneural edema, and axonal sprouting. Further studies using specific tools for small-fiber assessment are warranted to confirm these findings ${ }^{27}$.

Complex regional pain syndrome (CRPS/Sudeck's dystrophy) is a painful and disabling condition - a triad of autonomic, sensory, and motor symptoms disproportionate to the inciting event (inflammatory, infectious, or traumatic). A 20-year-old Indian male presented with continuous pain, aggravated by cold and emotions. A sensory and autonomic functions compromise along left radial and median nerve distribution were confirmed by nerve conduction studies suggestive of mononeuritis multiplex. Stellate ganglion block improved the pain scale. Excluding all other causes, the final diagnosis was CRPS type 2 secondary to leprosy. Very rarely leprosy can lead to CRPS ${ }^{28}$.

New tools for an early and better understanding of smallfibers damage are in development. Sensory damage has been best assessed by computerized quantitative sensory tests (QST), and the somatosensory pathways are being assessed by contact heat evoked potentials (CHEPS). The unmyelinated fibers of cornea can be easily examined by corneal confocal microscopy (CCM). We have observed that these methods improve the accuracy of diagnosis and treatment of this neuropathy $^{29}$. Studies are being conducted with these tools by our group for a better understanding of small-fiber neuropathy in leprosy, including a multicenter study for the treatment of pain in leprosy. We believe that chronic NP related to leprosy is due not only to the common peripheral nerve lesions but also to central sensitization at the spinal cord level.

\section{DIAGNOSIS}

According to experts, there are three diagnostic signs of leprosy: skin hypopigmentation with loss of sensation, thickening of peripheral nerves and skin-smear positive for the acid-fast bacilli. It is important to remember that indeterminate leprosy lesions are not always anesthetic and peripheral nerve thickness is also found in other neurological diseases. Recently, Brazilian leprosy experts proposed a systematic literature review on the current concepts of PNL consulting online databases (Garbino et al., 2013) ${ }^{30}$. Selected studies were classified based on the degree of recommendation and levels of scientific evidence according to the "Oxford Centre for Evidence-based Medicine". Evidence C and D was predominant in almost all clinical aspects of PNL, being the "neurological manifestations" the most proeminent with B reference level. They considered that the existing data is contradictory, and the methodology and objective of the studies are heterogeneous. Seemingly, the neuropathy of the PNL has a predominantly sensory involvement. Sensitivity to heat and pain are the most compromised, and in general, it has an asymmetric pattern of multiple mononeuropathy. Although leprosy neuropathy is diagnosed in clinical basis, there are cases mainly of PNL in which biopsy is the diagnosis gold standard method (Figure 1). The same can be considered for LLON cases diagnosis. Table 1 shows the principal clinical aspects of leprosy neuropathy.

\section{Electrodiagnostic (EDX) test}

Leprosy causes predominantly a secondary axonal neuropathy. Needle electromyography can disclose muscle denervation in some cases ${ }^{6}$. Near-nerve technique is a useful and sensitive method in detecting early small-fiber lesions but not routinely used by neurophysiologists in endemic countries. Demyelinating features can be also seen, mainly in the ulnar nerve across the elbow ${ }^{19}$.

\section{Differential diagnosis}

Usually in an endemic country there is no difficult to perform leprosy diagnosis facing a patient presenting with cutaneous sensory loss and mononeuropathy, or multiple mononeuropathy or polyneuropathy. On the other hand, 


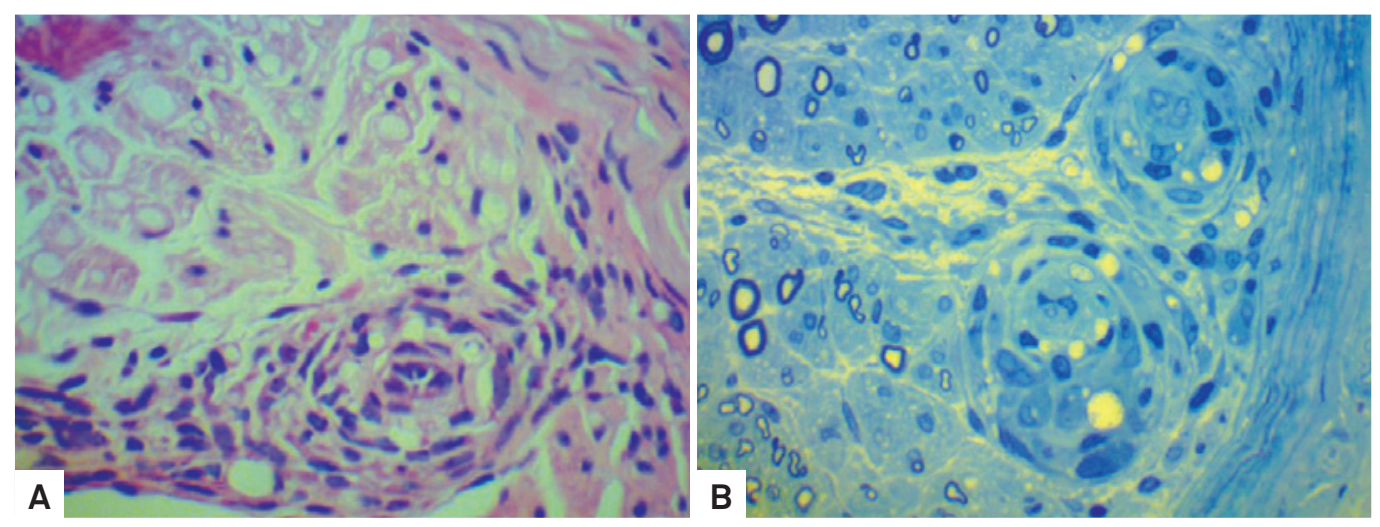

Figure 1. Leprosy neuropathy: nerve biopsy. Biopsy of the superficial branch of the ulnar nerve in the left hand. Patient previously fully treated with MDT for "skin leprosy" presenting two years later a painful multifocal neuropathy: in A, see inflammatory perivascular infiltrates in the endoneurium (H\&E x 40); and in B a semithin section showing macrophage foam cells containing fragmented bacilli in the blood vessel walls and in the endoneurium (T. blue x 100).

Tabela 1. Leprosy neuropathy clinical presentations.

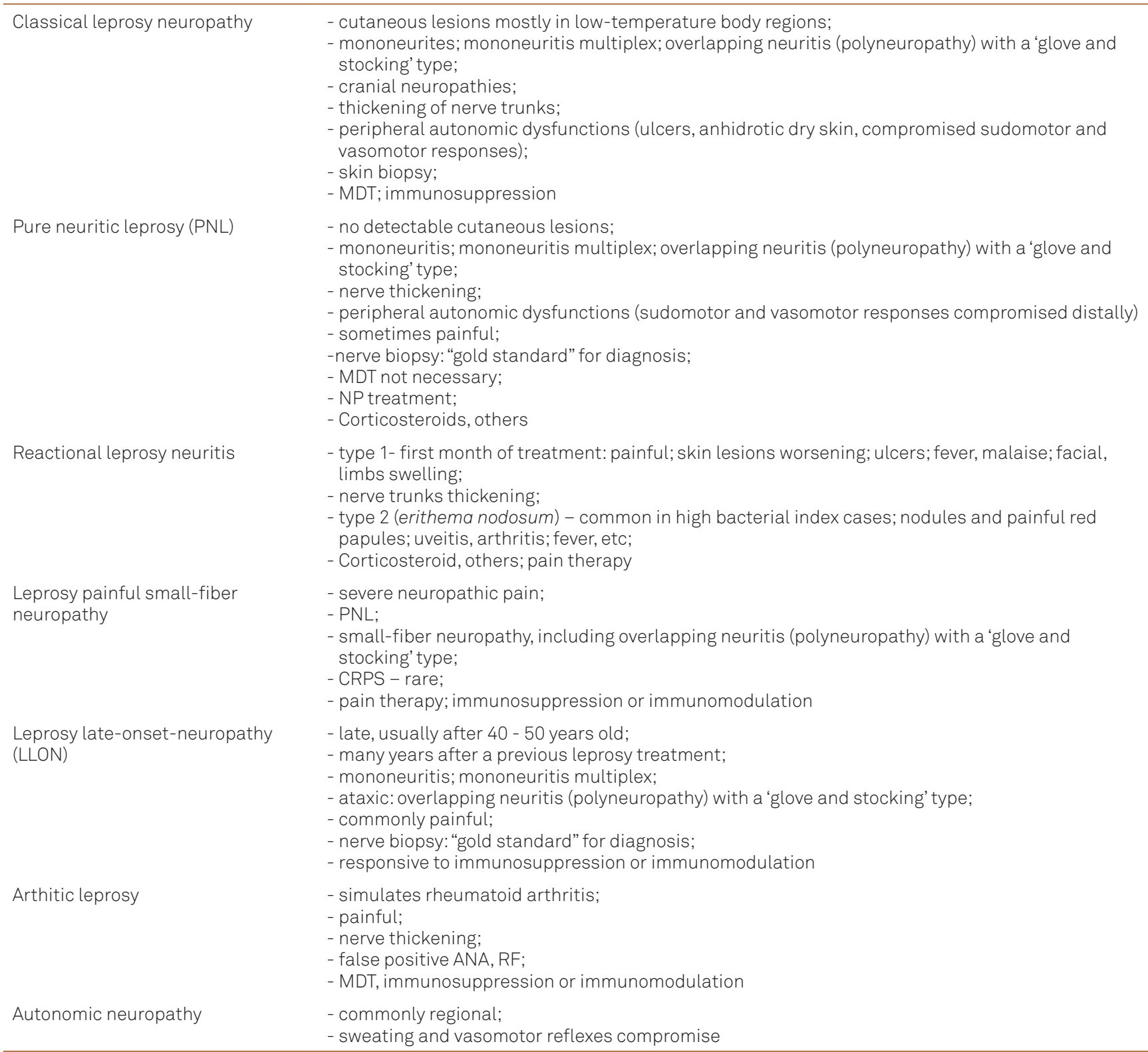

MDT: multi-drug therapy; NP: neuropathic pain; CRPS: complex regional pain syndrome; ANA: antinuclear antibody; RF: rheumatoid factor. 
when there are no skin lesions, encompassing a PNL, diagnosis becomes more difficult. Temperature and pain sensations are decreased early and vibration and position sense are frequently normal. Nerve thickness is present in high percentage being easily palpable. Although some neuropathies can have this clinical pattern those which frequently mimics leprosy are diabetic and amyloid neuropathy. Deep tendon reflexes are usually almost preserved in leprosy contrasting with these two conditions. Length-dependent pattern is not seen in leprosy. Compression or entrapment syndromes are sometimes difficult to exclude from leprosy mainly facing an ulnar neuropathy, for example. A biopsy of the involved superficial sensory nerve should be performed as the gold standard to confirm the diagnosis.

\section{CONCLUSION}

Leprosy neuropathy continues to be a health problem in poor developing countries of tropical and subtropical areas, but some cases has been recently reported in developed countries. The employment of prophylactic measures should play a main role in the eradication of this infectious neuropathy. A good epidemiological history and a precise clinical and neurological examination are needed. Early diagnosis and treatment is mandatory to avoid disabilities and deformities. Thereby, the recognition of the clinical forms of neuropathy of leprosy is one of the best tools for quick and accurate diagnosis avoiding these complications.

\section{References}

1. Van Brakel WH, Nicholls PG, Das L, et al. The INFIR cohort study: investigating prediction, detection and pathogenesis of neuropathy and reactions in leprosy, methods and baseline results of a cohort of multibacillary leprosy patients in North India. Lepr Rev 2005;76: 14-34.

2. Pasnoor M, Nascimento OJ, Trivedi J, et al. North America and South America (NA-SA) neuropathy project. Int J Neurosci 2013; Apr 17. [Epub ahead of print].

3. Pardal-Fernández JM, Rodríguez-Vázquez M, Fernández-Aragón G, Iñíguez-De Onzoño L, García-Muñozguren S. Leprosy and severe neuropathy in two native Spaniards. Rev Neurol 2007;45: 734-738.

4. De Freitas MRG, Nascimento OJM, Quaglino EAM, et al. Small-fiber polyneuropathy in leprosy without skin changes: study of 17 cases. Arq Bras Neuropsiquiatr 2003;61,542-546.

5. Blackwell JM. Modern genetics and leprosy susceptibility. Lepr Rev 2001;72:352-356.

6. Jardim MR, Antunes SLG, Santos AR, et al. Criteria for diagnosis of pure neural leprosy. J Neurol 2003; 250:606-809.

7. JardimMR,ChimelliL,FariaSCR,etal.Clinical,electroneuromyographic and morphological studies of pure neural leprosy in a Brazilian referral center. Lepr Rev 2004;75: 242-253.

8. Elias J Jr, Nogueira-Barbosa MH, Feltrin LT, et al. Role of ulnar nerve sonography in leprosy neuropathy with electrophysiologic correlation. J Ultrasound Med 2009; 28:1201-1209.

9. De Freitas MRG, Carvalho AAV, Nascimento OJM, et al. The difference by ultrasonography between ulnar neuropathy: entrapment or leprosy? J Neurol 2009;256(Suppl):S59.

10. Vital RT, Illarramendi X, Antunes SL, et al. Isolated median neuropathy as the first symptom of leprosy. Muscle Nerve 2013;48:179-184.

11. Gopinath DV, Thappa DM, Jaishankar TJ. A clinical study of the involvement of cranial nerves in leprosy. Indian J Lepr 2004;76:1-9.

12. Vaishampayan S, Borde P. An unusual case of isolated sixth cranial nerve palsy in leprosy. Dermatol Online J 2012;18:16.

13. Subbarao NT, Jaiswal AK. A case of leprosy with multiple cranial neuropathy mimicking Melkerson Rosenthal syndrome. Indian J Lepr 2011;83:101-102.

14. Prasad S, Misra R, Aggarwal A, et al. Leprosy revealed in a rheumatology clinic: a case series. Int J Rheum Dis 2013;16:129-133.

15. Salvi S, Chopra A. Leprosy in a rheumatology setting: a challenging mimic to expose. Clin Rheumatol. 2013 May 7. [Epub ahead of print].
16. Misra UK, Kalita J, Mahadevan A, Shankar SK. Pseudoathetosis in a patient with leprosy. Mov Disord 2003;18:598-601.

17. Khadilkar SV, Kasegaonkar PS, Ursekar M. Spinal cord involvement and ganglionitis in leprosy. Neurol India 2007;55:427-428.

18. Khadilkar SV, Benny R, Kasegaonkar PS. Proprioceptive loss in leprous neuropathy: a study of 19 patients. Neurol India 2008; 56:450-455.

19. Illarramendi X, Bührer-Sékula S, Sales AM, et al. High prevalence of vasomotor reflex impairment in newly diagnosed leprosy patients. Eur J Clin Invest 2005;35:658-665.

20. Soysal A, Atay T, Ozu T, Arpaci B. Electrophysiological evaluation of peripheral and autonomic involvement in leprosy. Can J Neurol Sci 2004; 31:357-362.

21. Vital RT, Illarramendi X, Nascimento 0 , et al. Progression of leprosy neuropathy: a case series study. Brain Behav 2012; 2:249-255.

22. Van Brakel W, Cross H, Declercq E, et al. Review of leprosy research evidence (2002-2009) and implications for current policy and practice. Lepr Rev 2010;81:228-275.

23. Nascimento OJM, de Freitas MRG, Escada T, et al. Leprosy lateonset neuropathy: an uncommon presentation of leprosy. Arq Neuropsiquiatr 2012;70:404-406.

24. Cardoso FM, de Freitas MRG, Escada TM, Nevares T, Nascimento OJ. Late onset neuropathy in leprosy patients. Late onset neuropathy in leprosy patients released from treatment: not all due to reactions? Lepr Rev 2013;84: (in press).

25. Rosemberg NR, Faber WR, Vermeulen M. Unexplained delayed nerve impairment in leprosy after treatment. Lepr Rev 2003;74:357-365.

26. Chen S, Qu J, Chu T. Prevalence and characteristics of neuropathic pain in the people affected by leprosy in China. Lepr Rev 2012;83: 195-201.

27. Garbino JA, Naafs B, Salgado MH, et al. Association between neuropathic pain and A-waves in leprosy patients with type 1 and 2 reactions.J Clin Neurophysiol 2011;28:329-332.

28. Ghia D, Gadkari R, Nayak C. Complex regional pain syndrome secondary to leprosy. Pain Med 2012;13:1067-1071.

29. Nascimento OJM, Davidovich E, Pupe C, et al. New useful and complementary tools for neuropathic pain/small fiber neuropathy diagnosis: contact heat-evoked potential stimulator (CHEPS) and corneal confocal microscopy (CCM). J Peripher Nerv Syst 2013; 18(Suppl): S77.

30. Garbino JA, Marques Jr W, Barreto JA, et al. Primary neural leprosy: systematic review. Arq Neuropsiquiatr 2013;71:397-340. 